\title{
A Descriptive Study to Assess the Knowledge Level Regarding Prevention of Medication Error among Students in Selected Nursing College, Kanpur
}

\author{
M Raghavendran*, Tapti Bhattarcharjee, R Revathi \\ NIMS University, Jaipur, Rajasthan, INDIA.
}

\begin{abstract}
Background: Errors during medication administration shows alarming frequency in hospital environment majorly in the areas like emergency, critical care etc. The process of medication administration used in hospital settings were categorized into 5 stages viz. ordering, transcripting, preparing, dispensing and administering of medicines. During this process an error can occur at any time. Hence the present study is planned to assess the knowledge level of students regarding prevention of medication errors and to associate knowledge level with selected demographic variables of student nurses. Methods: A descriptive survey research design and nonprobability convenient sampling technique was used to select 200 nursing students as samples. A structured knowledge questionnaire was used to collect data from samples. Results: The result shows that, Out of 200 Students, 129 (64.5\%) of them were having inadequate level of knowledge, $49(24.5 \%)$ had moderately adequate level of knowledge and $22(11 \%)$ having adequate level knowledge regarding prevention of medication error.
\end{abstract}

The mean of knowledge level was 34.80 and standard deviation is 10.22 The association between the knowledge levels regarding prevention of medication error with selected demographic variables of nursing students, shows No Significance. Conclusion: The study concludes that there is a deficit in knowledge level of students regarding prevention of medication errors.

Key words: Assess, Knowledge, Prevention, Medication Error, Nursing, Students.

Correspondence

M Raghavendran,

Ph.D, Nursing Scholar, NIMS University, Jaipur, Rajasthan, INDIA.

Email id: ragharev@gmail.com

DOI: 10.5530/ijpi.2021.3.57

\section{INTRODUCTION}

The first priority of health care professional is safety of patient during the hospital stay. Errors appearing in the hospital setting makes a lot which may cost high. Some of the incidents like falls in hospitals, use of wrong equipment, healthcare associated infections, inappropriate management of clinical condition and medication error. ${ }^{1}$ The health care discipline which was appeared advancing with the health care system complications and resulting in increased at patient harm among health care settings is patient safety. It mainly focuses in preventing and reducing the risk, errors and harm usually occurs to health care beneficiaries during the care. Patient safety is one of a basic element for delivering quality health services to the patients. Actually, there should be a unity in delivering the quality health service as effective, safe and people-oriented care globally. Clear policies, managing capacities, skilled professionals and effective involvement in patient care may helpful in ensuring proper implementation of patient safety. ${ }^{2}$

In a report by institute of medicine claims that merely 98,000 patients die each year due to errors during the care given in hospitals. ${ }^{3}$ Errors during medication administration shows alarming frequency in hospital environment majorly in the areas like emergency, critical care etc. ${ }^{4}$ Since the report from Institute of Medicine (1999) safety policies in health care settings were initiated and also WHO started the International movement for patient safety lead to initiate changes in the practices carrying out in clinical settings. Various barriers of safe practices were analysed for safety culture in health care settings by many studies and they identified the cause of adverse events in the opinion of health professionals and their training needs. ${ }^{5}$

In human life errors are one of an inherent part. Errors usually emerge as a natural process of intellectual and behavioural transformation to correct behavioural skills. An important aspect of healing process and care of patient is performing medical order also a main part in nursing performance also have a major role in caring patient. Safety of a patient may significantly affect by medication errors and also increases the cost of treatment and results in threat for patients and to their families. It may also lead to some unpleasant results like rise in mortality, increase stay in hospital days and also increases medical expenses. Even medication errors can be due to any health care member, it is most common among nurses because they are only performing medication administration merely $40 \%$ of their duty time. It is well known that the rate of medication error by nurses are high in both developed and developing countries. ${ }^{6}$ Medication errors are well known problem in clinical setting. Many studies states that the main cause of adverse event happens in health care settings are due to medication errors and adverse drug reactions. These types of errors may not cost to loss of life, it also makes financial burden, physical or psychological related pain rather than that these errors may reduce the trust and satisfaction level of patients towards the health care system and also with the providers. ${ }^{7}$

Merely 7000 people were affected annually due to medication error. In India, problems related to medication and errors due to medicine are due

This is an open access article distributed under the terms of the Creative Commons Attribution-NonCommercial-ShareAlike 4.0 License, which allows others to remix, tweak, and build upon the work non-commercially, as long as the author is credited and the new creations are licensed under the identical terms. 
to use of irrational medicines. ${ }^{8}$ The process of medication administration used in hospital settings were categorized into 5 stages viz. ordering, transcripting, preparing, dispensing and administering of medicines. During this process an error can occur at any time. Majority of errors occurring in this process are (53\%) during administering of medication, secondly $(17 \%)$ is when ordering the medication followed by $(14 \%)$ preparation and finally during transcripting (11\%). If an error didn't result in harm is referred as near miss. Unnecessary harm and altering in planned therapeutic effects were majorly occurred by using inappropriate abbreviations, so it is important to use error prone abbreviations. This problem has been reduced by fast development of electronic usage during prescription. But still, most of the developing countries are using hand written prescriptions. ${ }^{9}$

Medication errors can also happen due to communication barriers, because physician many times may give oral orders which may lead to error due to the fact that most of names of drugs are sound like and may mispronounced. Some other more causes are said to be wrong patient, improper dosage of medicine, wrong medicine and improper route. ${ }^{10}$

A huge amount of attention has been made in nursing practice is medication error. Many of these errors are self-reported and to be recorded. The incidence varies according to population. The paediatric and elderly patients are more likely to harm by these types of error. Children are more likely to have dosage errors and older will take more medications. These errors are likely to occur in stressful and fast paced environment like emergency rooms, ICU's and in some clinical areas. Data given by Food and Drug Administration (FDA) shows improper dose of medicine accounts $41 \%$ and $16 \%$ of errors are due to wrong route administration. ${ }^{11}$ Hence the present study is aimed to assess the knowledge level regarding prevention of medication error among nursing students and to associate the knowledge level with selected demographic variables of nursing students.

\section{Methodology}

A non-experimental research approach with descriptive research design was conducted after obtaining permission from selected nursing colleges in kanpur. Around 200 nursing students from different branches like diploma in nursing (GNM), and bachelor's degree in nursing like B.Sc $(\mathrm{N})$ and Post Basic B.Sc $(\mathrm{N})$ were selected as samples. The study participants are selected by convenient sampling technique and on voluntary basis. Level of knowledge on prevention of medication error was selected as research variable under study. A structured multiple-choice questionnaire was used to collect the data from the samples.

The structured questionnaire comprised of two sections viz. Section 1 consists of Demographic data of the samples like Age, Gender, Educational Status, Previous Knowledge regarding prevention of medication error. Section 2 consists of structured questionnaire with 20 multiple choice items to assess the knowledge level regarding prevention of medication error among nursing students. The questions were covered the variety of topics like preparation of medication, dispersion of medication, administration methods and differentiation of lookalike and soundalike medications and nurse's role in preventing the medication error. Each correct answer carry (1) mark and each wrong answer carry (0) mark. Total 20 marks. The questionnaire was administered to all the students individually and the data were analysed by using descriptive statistics like frequency and percentage distribution, mean and standard deviation and inferential statistics like chi-square test to assess the association between knowledge with selected demographic variables.

\section{RESULTS}

\section{Frequency and Percentage Distribution of Nursing} Students

Frequency and percentage distribution of demographic variable of nursing students is summarized in Table 1 . With regards to age $172(86 \%)$ were between 22 -23 years of age, 17 (8.5\%) were between 23 -24 years and the age group of $24-25$ years with 31 (5.5\%). With respect to gender, mostly $184(92 \%)$ were females and $16(8 \%)$ were males. According to education status of students, 82 (41\%) were GNM, 93 (46.5\%) were B.Sc students and Post Basic B.Sc (N) students were 25 (12.5\%). With regard to Previous Knowledge on prevention of Medication Error, 38 (19\%) were had previous knowledge and $162(81 \%)$ had no previous knowledge regarding prevention of Medication Error

\section{Knowledge level regarding prevention of medication error}

Knowledge level regarding prevention of medication error among nursing students was summarized in Table 2 and Figure 1. Out off 200 Students $129(64.5 \%)$ of them were having inadequate level of knowledge, 49 (24.5\%) had moderately adequate level of knowledge and $22(11 \%)$ having adequate level of Knowledge Level on prevention of medication error. Mean and standard deviation of Knowledge Level on prevention of medication error are 34.80 and 10.22 respectively.

\section{Association between the Knowledge Level on prevention of medication error with the selected demographic variables}

The association between the Knowledge Level on prevention of medication error with selected demographic variables of nursing students, shows No Significance

\section{DISCUSSION}

Out-off 200 students, 93 (48\%) of students were B.Sc (N) final year and $184(92 \%)$ of students were females. With respect to age $172(86 \%)$ were 22 - 23 years of age. With regard to knowledge level, 129 (64.5\%) of them were having inadequate level of knowledge, 49 (24.5\%) had moderately adequate level of knowledge and 22 (11\%) having adequate

Table 1: Frequency and Percentage Distribution of Nursing Students. $(n=200)$.

\begin{tabular}{cccc}
\hline S.No & Demographic Variable & Frequency & Percentage \\
\hline 01 & Age: & 172 & \\
& $22-23$ & 17 & 86 \\
& $23-24$ & 11 & 5.5 \\
& $24-25$ & & \\
02 & Gender: & 16 & 8 \\
& Male & 184 & 92 \\
03 & Female & & \\
& Education status: & 82 & 41 \\
& GNM & 93 & 46.5 \\
& B.Sc (N) & 25 & 12.5 \\
& P.B.B.Sc (N) & & \\
& Previous Knowledge on & & 19 \\
& prevention of Medication Error & & 81 \\
\hline
\end{tabular}


Table 2: Frequency and percentage distribution of Knowledge level regarding prevention of medication error among student nurses. $(n=200)$

\begin{tabular}{ccc}
\hline Knowledge Level & Frequency & Percentage \\
\hline Inadequate Level & 129 & 64.5 \\
Moderately Adequate Level & 49 & 24.5 \\
Adequate Level & 22 & 11.0 \\
Total & 200 & 100.0
\end{tabular}

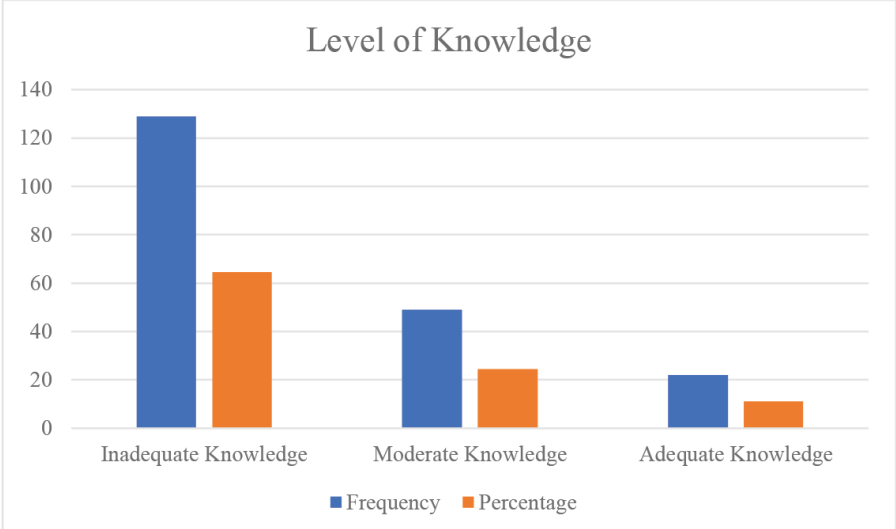

Figure 1: Bar diagram shows the frequency and percentage distribution of Knowledge Level on prevention of medication error.

level of Knowledge Level on prevention of medication error. The result was supported by the study done by Cebeci F. There is no replacement for the role of nurses for providing health care. There is no proper error reporting system in Turkey, there are only approximate numbers about the errors in medication. A cross sectional study was done with an aim to assess the number and type of medication error made by nursing students. Total of 324 nursing students those who had worked in clinical setting for one semester were selected by purposive sampling technique. The study result shows that 124 (38.3\%) of samples out off 324 had accepted that they made errors during clinical postings and the most common error was improper aseptic technique which was 96 (23.8\%). With regard to emotion during error, $45(28.8 \%)$ reported fear and $37(23.5 \%)$ reported anxiety. With respect to cause of error $141(43.4 \%)$ of samples reported performance deficit and workload was most common contributing factor 179 (55.2\%). The study concluded that the error rate made by the nurses was high but the reporting of error was low. ${ }^{12}$ The association between the Knowledge Level on prevention of medication error with selected demographic variables of nursing students, shows No Significance

\section{Implication of the study}

The scientific and technological developmental is challenged to nursing to keep with new developments in continuing education. Educational programme plays a major factor on shaping the future of the profession of nursing service. In Nursing Education, Nursing may be defined as a therapeutic and educative process in meeting health need of society the present study emphasises that knowledge level on prevention of medication error. It is essential that student nurses have to gain knowledge on medication error so that they may reduce the incidence of occurring errors.

In nursing Research, It helps to acquire some reasonable answer to an event or phenomena along with the inquiry on scientific procedure, its aim, neutral, actual and logical analysis may lead to the expansion of principles of theory, resulting in development of forecasting and control of events that may be the consequences or may cause of specific phenomena. The finding of the present study can be utilised by researchers in nursing has to contribute the profession to acquire new knowledge regarding prevention of medication error. Publication and presentation often inhibit rather than support research-based practice. Clearly delineate practice implication of result.

\section{CONCLUSION}

The study concludes that the student nurses have less knowledge level on prevention of medication error. It is important to provide proper education so that the error can be prevented in future.

\section{CONFLICT OF INTEREST}

The authors declare no conflict of interest.

\section{ABBREVIATIONS}

WHO: World Health Organization; GNM: General Nursing and Midwifery.

\section{REFERENCES}

1. Athanasakis E. Prevention of medication errors made by nurses in clinical practice. Health Sci J. 2012;6(4):773-83.

2. Fundamentals in patient safety. Available in https://www.who.int/patientsafety/ education/curriculum/course1_handout.pdf [Last assessed on 27/07/2021]

3. Banfi G, Magon G, Maniaci G, Vinci A. Presentation of a draft of nursing research. Padova: Piccin; 2007. Methodology in nursing research and clinical risk. Fronte theory to prescrive. p. 19-50.

4. Mira JJ, Navarro IM, Guilabert M, Poblete R, Franco AL, Jiménez P, Aquino M, Fernández-Trujillo FJ, Lorenzo S, Vitaller J, de Valle YD, Aibar C, Aranaz JM, De Pedro JA. A Spanish-language patient safety questionnaire to measure medical and nursing students' attitudes and knowledge. Rev Panam Salud Publica. 2015;38(2):110-9. PMID 26581051

5. Samundeeswari A. Nurses Knowledge on Prevention of Medication Error jmscr. 2018;6(3). doi: 10.18535/jmscr/v6i3.45.

6. Di Simone ED, Giannetta N, Auddino F, Cicotto A, Grilli D, Di Muzio M. Medication errors in the emergency department: Knowledge, attitude, behavior, and training needs of nurses. Indian J Crit Care Med. 2018;22(5):346-52. doi: 10.4103/ijccm. IJCCM_63_18.

7. Cheragi MA, Manoocheri H, Mohammadnejad E, Ehsani SR. Types and causes of medication errors from nurse's viewpoint. Iran J Nurs Midwif Res. 2013;18(3):228-31. PMID 23983760

8. Tariq RA, Vashisht R, Sinha A, Scherbak Y. Medication dispensing errors and prevention. Available in https://www.ncbi.nlm.nih.gov/books/NBK519065/ [Last assessed on 27/07/2021].

9. Patel S, Patel A, Patel V, Solanki N. Study of medication error in hospitalised patients in tertiary care hospital. IJOPP. 2018;11(1):32-6. doi: 10.5530/ijopp.11.1.6.

10. Agrawal P, Sachan A, Singla RK. Statistical analysis of medication errors in Delhi, India. Indo Glob J Pharm Sci. 2012;2(1):88-97.

11. Avillion A. Prevention of medical errors in Nursing. Elite Prof Educ. 2016:10-20

12. Cebeci F, Karazeybek E, Sucu G, Kahveci R. Nursing students' medication errors and their opinions on the reasons of errors: A cross-sectional survey. J Pak Med Assoc. 2015;65(5):457-62. PMID 26028376.

Article History: Submission Date : 07-07-2021; Revised Date : 06-08-2021; Acceptance Date : 27-08-2021.

Cite this article: Raghavendran M, Bhattarcharjee T, Revathi R. A Descriptive Study to Assess Knowledge Level Regarding Prevention of Medication Error among Students in Selected Nursing College, Kanpur. Int. J. Pharm. Investigation. 2021;11(3):324-6. 